•研究报告・

\title{
大亚湾底拖网海洋生物种类组成及物种多样性
}

\author{
张敬怀 ${ }^{*}$ 高阳 时小军吕向立
}

(国家海洋局南海环境监测中心, 广州 510300)

\begin{abstract}
摘要: 为了能够掌握大亚湾物种多样性状况, 本文利用2004-2015年大亚湾底栖生物调查底拖网数据, 研究了该 海域的生物种类组成、优势种及物种多样性的时空变化。结果表明: 2004-2015年共获得海洋动物429种，隶属于 10 门 16 纲 175 科 309 属, 各航次物种数变化范围在 $75-114$ 种之间, 不同年份、季节均以软体动物、节肢动物和鱼类为 主要生物类群; 大亚湾物种数量的空间分布存在差异, 春季在2007年前基本呈现海湾西部高于东部的趋势, 夏季 在2008年前则呈现向海湾西南部升高的趋势, 之后不同季节则基本呈现湾口高于湾内北部、东部高于西部的趋势; 大亚湾的主要优势种具有一定的季节性变化, 春季常以鳞片帝汶蛤(Timoclea imbricata)或波纹巴非蛤(Paratapes undulatus)优势度最高, 夏季2004-2007年间优势度最高的优势种经常变化, 2008年后则以棒锥螺(Turritella bacillum) 优势度最高, 秋季棒雉螺或鳞片帝汶蛤优势度最高; 2004年后大亚湾底拖网物种多样性呈逐渐降低的趋势, 特别是海湾北部物种多样性下降严重, 受人类活动的干扰较大。目前, 大亚湾的局部区域承担了整个海湾物种多 样性的维持功能, 底栖生态系统相对更加脆弱。
\end{abstract}

关键词: 南中国海; 大型底栖生物; 定性调查; 物种多样性; 优势种

\section{Species composition and diversity of marine organisms from benthic trawling in Daya Bay of the northern South China Sea}

\author{
Jinghuai Zhang ${ }^{*}$, Yang Gao, Xiaojun Shi, Xiangli Lü \\ South China Sea Environmental Monitoring Center, State Oceanic Administration (SOA), Guangzhou 510300
}

\begin{abstract}
Based on data from benthic trawling in Daya Bay between 2004 and 2015, the temporal and spatial characteristics of species composition and diversity were analyzed. A total of 429 species of marine animals were identified, belonging to 10 phyla, 16 classes, 175 families, and 309 genera. Species numbers varied between 75-114 in Daya Bay between 2004 and 2015. Chordata, Arthropoda, and Mollusca were the dominant phyla from 2004 to 2015, respectively. Species numbers showed a decreasing trend from 2004 to 2015. In the spring, the species number was higher in the western part of Daya Bay than the eastern region before 2007. More recently, the species number was higher in the mouth and the eastern parts of Daya Bay than the northern and western regions. In the summer, the species numbers increased in the southwestern region of the bay before 2008, but after 2009 results showed that the species number was higher in the mouth of the bay than the inner region. Timoclea imbricata or Paphia undulata were the first dominant species in spring. In summer, the first dominant species varied before 2007, but Turritella bacillum was the most dominant species after 2008. In autumn, Timoclea imbricata or Turritella bacillum was the first dominant species. The average Shannon-Wiener diversity index $\left(H^{\prime}\right)$, Pielou's evenness index $\left(J^{\prime}\right)$, and species richness index (d) varied between 1.46-4.05, 0.30-0.89 and 2.49-6.69, respectively. Diversity decreased in Daya Bay between 2004 and 2015, especially in the northwestern area, mainly due to heavy anthropogenic activities. In recent years, the species resources of some areas of Daya Bay contribute mostly to the function of species diversity of the whole bay in the past, and benthic ecosystems have become more fragile.
\end{abstract}

Key words: South China Sea; macrobenthos; qualitative investigation; species diversity; dominant species

收稿日期: 2017-03-27; 接受日期: 2017-06-02

基金项目: 国家自然科学基金(41406179, 41776172)

* 通讯作者 Author for correspondence. E-mail: zhangjinghuai@sohu.com 
大亚湾位于南中国海的北缘, 为半封闭海湾, 是我国南海北部重要的生物种质资源自然保护区 之一。近年来, 周边工业、港口、滨海旅游业和养 殖业等迅速发展, 导致海岸线改变、湿地减少、入 海排污量增加以及沿岸水动力状况改变, 使大亚湾 海域的生态环境发生了较大的变化, 如红树林退 化、造礁石珊瑚群落分布改变、海洋生物多样性降 低和赤潮频发等问题(王肇鼎等, 2003; 王友绍等, 2004; 王雪辉等, 2010; 李纯厚等, 2015)。

底栖生物生活在海洋底层, 是海洋生态环境变 化的优良指示生物(蔡立哲, 2006)。底拖网(定性调 查)是海洋底栖生物调查的一项重要手段, 相对于 定量采泥, 底拖网采样面积更大, 除可采到一些生 活在海底表层的大个体生物, 也可获得一些具有一 定游泳能力、经常或临时生活在海底的鱼类。20世 纪90年代, 大亚湾海洋开发的初期, 底栖生物定性 定量调查已经在该海域开展, 研究者分析了其种类 组成、生物数量和群落状况(徐恭昭, 1989; 江锦祥 等, $1990 \mathrm{a}, \mathrm{b})$, 为开展大亚湾底栖生物学研究积累 了大量的基础资料。近年关于大亚湾底栖生物研究 主要采用定量采泥的方法, 分析了海湾大型底栖生 物种类组成、分布、次级生产力、群落状况、多样 性水平等指标, 发现底栖生物多样性出现了一定程 度的降低, 而利用底拖网数据研究生物多样性的报 道较少(张敬怀等, 2007; 杜飞雁等, 2008, 2011)。本 文根据2004-2015年大亚湾海域底拖网调查结果, 分析了该海域海洋生物种类组成、优势种及物种多 样性等的时空变化, 探索了海湾海洋生物多样性在 人类干扰下的长期变化趋势, 可为生物多样性保护 和管理提供科学依据。

\section{1 采样及数据处理}

\section{1 调查时间及区域}

2004-2015年, 国家海洋局南海环境监测中心 对大亚湾海域底栖生物多样性进行了跟踪监测, 其 中夏季开展了 12 个航次、春季 7 个航次、秋季 3 个航 次。在大亚湾海域共布设 15 个监测站位(图1), 其中 6 个站进行了 12 年监测, 3 个站进行了 11 年监测, 另有 6 个站进行了 5 年监测。

\section{2 调查与分析方法}

按《海洋调查规范 第6部分: 海洋生物调查指 南》(GB/T 12763.6-2007)推荐的底栖生物调查方法,

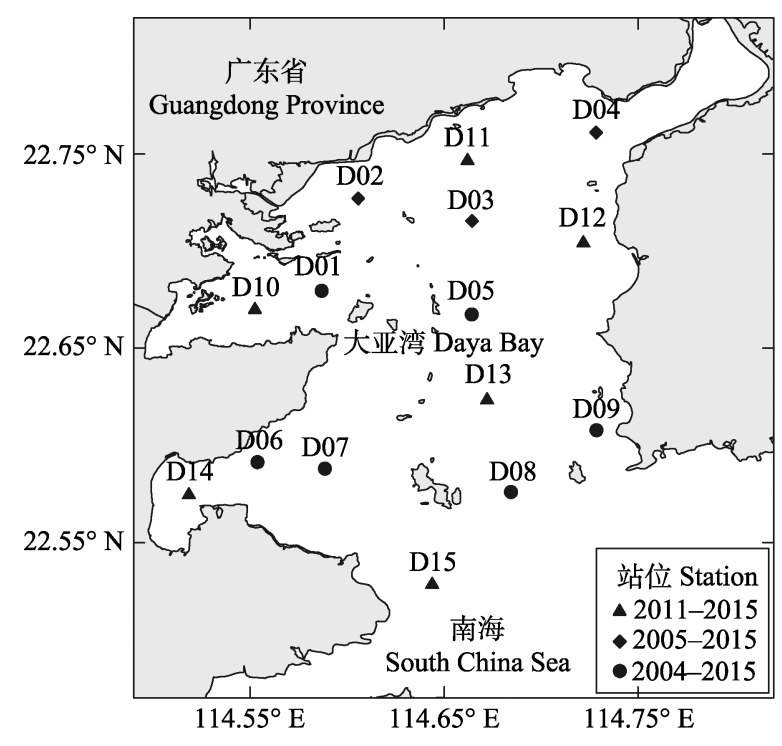

图1 大亚湾调查区域和站位

Fig. 1 Survey area and sampling stations in Daya Bay

使用宽 $1.5 \mathrm{~m}$ 的阿氏拖网慢速在海底拖曳约 $1,000 \mathrm{~m}$ 采集海洋生物, 现场将所有生物 $-20^{\circ} \mathrm{C}$ 冰冻保存, 在国家海洋局南海环境监测中心生物生态实验室 进行种类鉴定。海洋生物种类鉴定主要参考中国动 物志或地方动物志(魏崇德和陈永寿, 1991; 李思忠 和王惠民，1995; 廖玉麟，1997，2004; 周红等， 2007)、世界及中国海的生物学专著(戴爱云等, 1986; 董正之, 1991)、南海生物学专著(中国科学院动物研 究所等, 1962; 刘瑞玉和钟振如，1986)以及中国海 的生物图谱或图集(张凤瀛等, 1964; Qi, 2004; 黄宗 国和林茂, 2012)等。生物拉丁文名与世界海洋生物 种记录(WoRMS) (http://www.marinespecies.org)进 行核对。

\section{3 数据分析}

不同航次的种类相似性分析采用 Jaccard指数 $(J$, Jaccard, 1908)。海区优势种的判定采用物种优势度 $(Y)$, 定义优势度大于 0.02 为海区优势种(徐兆礼和 陈亚㫿，1989)，并按优势度大小排序。采用 Shannon-Wiener多样性指数 $\left(H^{\prime}\right) 、$ Pielou均匀度指数 $\left(J^{\prime}\right)$ 及种类丰富度指数 $(d)$ (Margalef, 1958)分析群落 物种的多样性, 各指数的计算公式如下:

$$
\begin{aligned}
& J=c /(a+b-c) \\
& Y=\left(n_{i} / N\right) \times f_{i} \\
& H^{\prime}=-\sum_{i=1}^{\mathrm{s}} p_{i} \log _{2}\left(p_{i}\right)
\end{aligned}
$$




$$
\begin{aligned}
& J^{\prime}=H^{\prime} / \log _{2} S \\
& d=(S-1) / \log _{2} N
\end{aligned}
$$

式中, $a 、 b$ 为两航次各自的物种(科或属)数, $c$ 为两航 次共有的物种(科或属)数, $n_{i}$ 为第 $i$ 种的个体数, $N$ 为 该航次或站底拖网样品中标本总个体数, $f_{i}$ 为该种 在各站出现的频率, $P_{i}$ 为测站第 $i$ 种的个体数与样品 总个体数的比值, $S$ 为测站样品的总种数。

图表分别利用软件 Microsoft Excel 2010、 Surfer 11.0和Adobe Photoshop cs2制作。

\section{2 结果}

\section{1 大亚湾底拖网海洋生物种类组成}

2004-2015年大亚湾底栖生物拖网共获得海洋 动物 429 种, 隶属于 $10 门 16$ 纲 175 科 309 属, 未采集
到大型海藻类。软体动物(127种)、节肢动物(122种) 和鱼类(116种)为种类最多的 3 个生物类群, 共占总 物种数的 $80 \%$ 以上, 其次为棘皮动物、环节动物和 腔肠动物, 其他类群(螠虫动物、纽形动物、海绵动 物和尾索动物)虽有出现, 但种类较少(表1)。春季(7 个航次)共获得10门14纲132科211属276种海洋动物, 夏季(12个航次)共获得 10 门16纲 155 科263属 351 种 海洋动物, 秋季(3个航次)仅获得 $7 门 11$ 纲78科111属 140 种海洋动物。

\section{2 大亚湾物种数量的时空变化}

2004-2015年各航次物种数量在75-114种之间, 物种数量随时间总体呈降低的趋势，但物种数量在 2012 年前呈现随时间连续性上升或降低的规律 (2009年夏季除外), 而2012年后海区物种数基本维

表 $12004-2015$ 年大亚湾底拖网生物种类组成

\begin{tabular}{|c|c|c|c|c|c|c|c|c|c|}
\hline $\begin{array}{l}\text { 季节 } \\
\text { Season } \\
\end{array}$ & $\begin{array}{l}\text { 年 } \\
\text { Year }\end{array}$ & $\begin{array}{l}\text { 脊索动物 } \\
\text { Chordata }\end{array}$ & $\begin{array}{l}\text { 节肢动物 } \\
\text { Arthropoda }\end{array}$ & $\begin{array}{l}\text { 软体动物 } \\
\text { Mollusca }\end{array}$ & $\begin{array}{l}\text { 棘皮动物 } \\
\text { Echinodermata }\end{array}$ & $\begin{array}{l}\text { 环节动物 } \\
\text { Annelida }\end{array}$ & $\begin{array}{l}\text { 刺胞动物 } \\
\text { Cnidaria }\end{array}$ & $\begin{array}{l}\text { 其他类群 } \\
\text { Others }\end{array}$ & $\begin{array}{l}\text { 合计 } \\
\text { Sum }\end{array}$ \\
\hline \multirow{8}{*}{$\begin{array}{l}\text { 春季 } \\
\text { Spring }\end{array}$} & 2004 & 19 & 35 & 41 & 6 & 2 & 4 & 1 & 108 \\
\hline & 2005 & 19 & 28 & 28 & 4 & 1 & 2 & 2 & 84 \\
\hline & 2006 & 22 & 33 & 43 & 7 & 3 & 5 & 0 & 113 \\
\hline & 2007 & 22 & 22 & 31 & 8 & 2 & 2 & 2 & 89 \\
\hline & 2008 & 19 & 33 & 25 & 5 & 1 & 3 & 0 & 86 \\
\hline & 2012 & 13 & 30 & 22 & 4 & 4 & 3 & 1 & 77 \\
\hline & 2013 & 10 & 31 & 34 & 5 & 6 & 6 & 2 & 94 \\
\hline & 小计 Subtotal & 62 & 79 & 87 & 19 & 13 & 11 & 5 & 276 \\
\hline \multirow{13}{*}{$\begin{array}{l}\text { 夏季 } \\
\text { Summer }\end{array}$} & 2004 & 18 & 38 & 28 & 6 & 1 & 1 & 2 & 94 \\
\hline & 2005 & 38 & 33 & 32 & 5 & 0 & 4 & 2 & 114 \\
\hline & 2006 & 13 & 30 & 43 & 2 & 5 & 5 & 0 & 98 \\
\hline & 2007 & 27 & 17 & 29 & 2 & 1 & 1 & 1 & 78 \\
\hline & 2008 & 30 & 28 & 26 & 4 & 1 & 2 & 1 & 92 \\
\hline & 2009 & 20 & 25 & 24 & 5 & 0 & 0 & 1 & 75 \\
\hline & 2010 & 16 & 28 & 42 & 1 & 2 & 4 & 2 & 95 \\
\hline & 2011 & 24 & 34 & 37 & 5 & 5 & 4 & 0 & 109 \\
\hline & 2012 & 22 & 33 & 34 & 4 & 5 & 2 & 1 & 101 \\
\hline & 2013 & 14 & 24 & 31 & 1 & 3 & 4 & 2 & 79 \\
\hline & 2014 & 15 & 28 & 28 & 2 & 0 & 3 & 2 & 78 \\
\hline & 2015 & 22 & 33 & 32 & 4 & 6 & 3 & 3 & 103 \\
\hline & 小计 Subtotal & 97 & 96 & 105 & 16 & 19 & 14 & 4 & 351 \\
\hline \multirow{4}{*}{$\begin{array}{l}\text { 秋季 } \\
\text { Autumn }\end{array}$} & 2011 & 24 & 31 & 27 & 3 & 3 & 2 & 1 & 91 \\
\hline & 2012 & 25 & 32 & 20 & 1 & 0 & 1 & 1 & 80 \\
\hline & 2013 & 16 & 27 & 29 & 1 & 2 & 3 & 1 & 79 \\
\hline & 小计 Subtotal & 37 & 50 & 40 & 3 & 4 & 5 & 1 & 140 \\
\hline 总计 Total & & 116 & 122 & 127 & 22 & 21 & 16 & 5 & 429 \\
\hline
\end{tabular}

Table 1 Species composition from benthic trawling in Daya Bay between 2004 and 2015 
持在相对较低水平(80种左右) (图2)。相对2004年春 季, 各航次生物类群种水平的种类相似性指数平均 值在 $30 \%$ 左右，属水平在 $35 \%$ 左右，而科水平在 45\%左右, 不同分类级别变化规律基本相同, 均呈 现轻微的逐渐降低的趋势; 不同季节种类相似性的 变化规律不明显(图3)。

大亚湾底拖网物种数量的空间分布存在季节 和年际尺度的变化(图4, 图5)。春季在2007年前基本 呈现海湾西部高于东部的趋势, 湾口的物种数并不 显著高于其他区域，但2008年、2012年和2013年的3 次调查则呈现湾口和东部高于北部和西部的趋势。 夏季在2004-2008年间虽然基本表现为湾口高于湾 内的趋势, 但有向湾西南部升高的趋势; 2009年后 基本呈现湾口高于湾内的趋势, 但不同年份物种数 高值区的空间分布变化较大，如2009年和2013年湾 西南部D09站、2010年和2015年湾中部的D05站及 2011年湾西北部的D01站物种数相对较高。2011年 后开展的秋季调查, 则基本呈现湾东部和湾口高于
西部和湾内西北部的趋势。

\section{3 大亚湾底拖网海洋生物优势种}

大亚湾底拖网海洋生物优势种的统计结果见 表2-3, 不同航次调查海区优势种如下:

(1)鱼类长鯺蓝子鱼(Siganus canaliculatus)、基 岛䲝 (Callionymus kaianus) 和四线天竺鲷 (Ostorhinchus fasciatus)。长鯺蓝子鱼和四线天竺鲖春季 出现频率较低, 夏季常为大亚湾优势种。基岛䱦不 同季节均经常出现, 2011年前常为优势种。

(2)棘皮动物海参纲的海地瓜 (Acaudina molpadioides)、海胆纲的扁拉文海胆(Lovenia subcarinata) 和蛇尾纲的光滑倍棘蛇尾(Amphioplus laevis)。 海地瓜不同季节的出现频率不高, 仅在2004年和 2008年夏季为优势种。扁拉文海胆春季经常出现, 夏、秋季不常见，仅在2004年春、夏为优势种。光 滑倍棘蛇尾不同季节常出现，在2011年和2012年夏 季为优势种。

(3)甲壳动物口虾蛄(Oratosquilla oratoria)、须赤

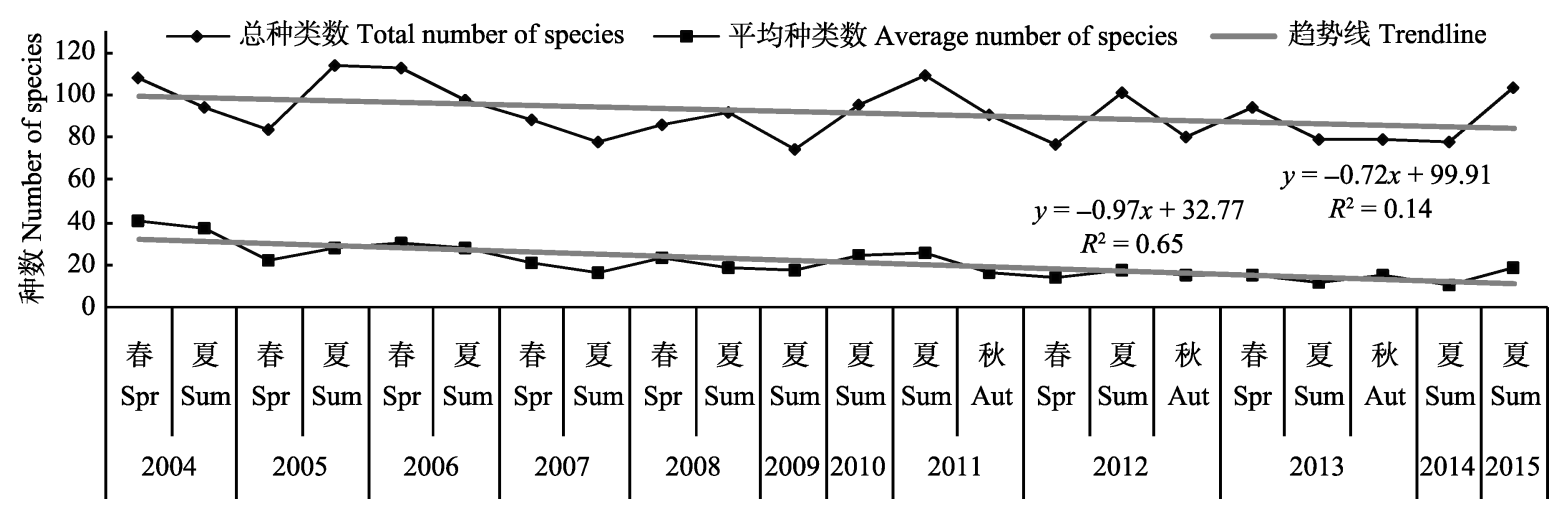

图2 2004-2015年大亚湾底拖网物种数变化规律

Fig. 2 Variation of species number from benthic trawling in Daya Bay between 2004 and 2015



图3 与2004年春季相比, 2004-2015年大亚湾底拖网生物种、属和科相似性指数变化图

Fig. 3 In compare to spring 2004, varieties of Jaccard index of marine organisms from benthic trawling at species, genus and family levels in Daya Bay between 2004 and 2015 

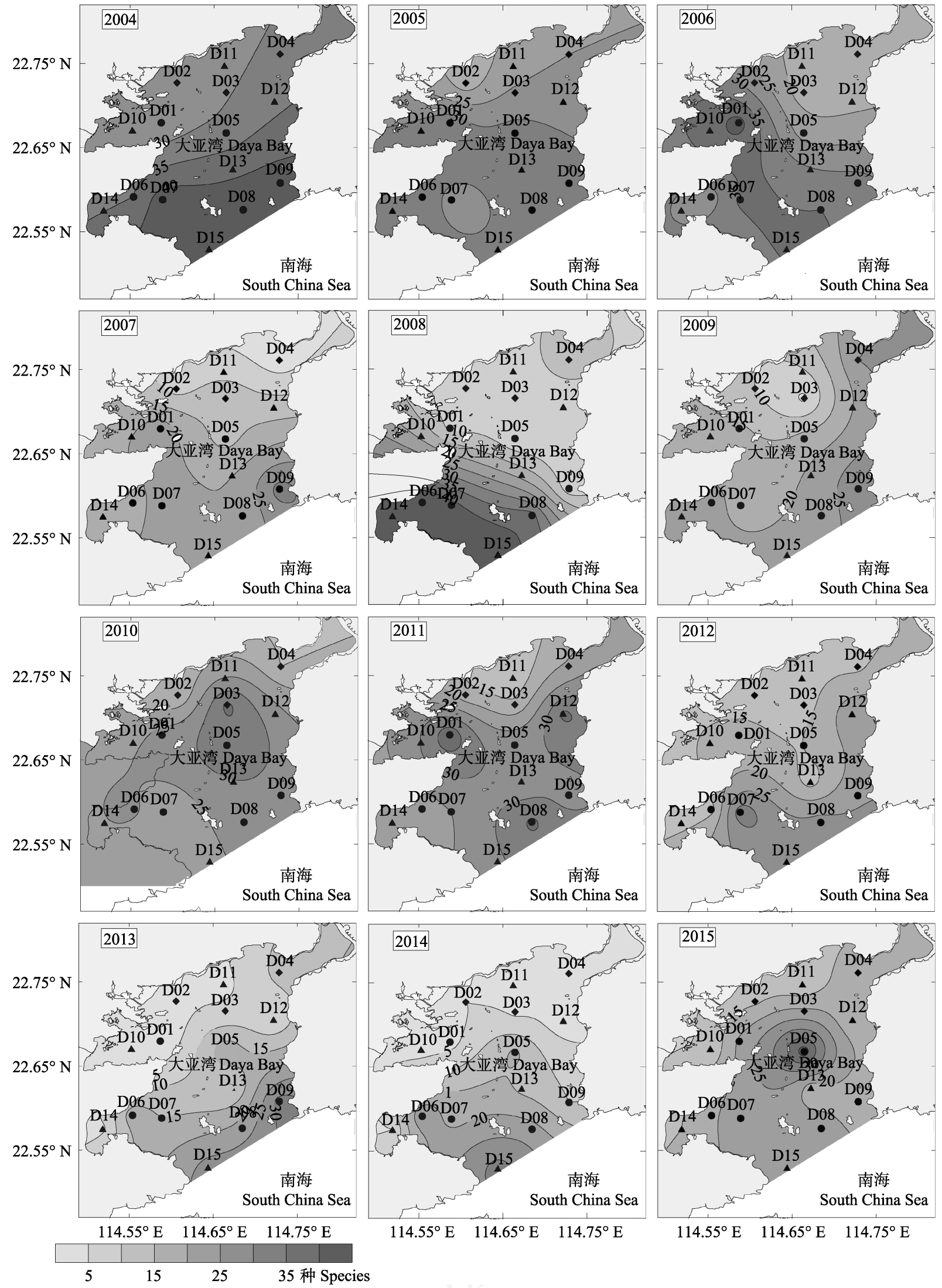

图4 2004-2015年夏季大亚湾底拖网物种数量的空间变化

Fig. 4 Contour map of species number from benthic trawling in Daya Bay in summer from 2004 to 2015 

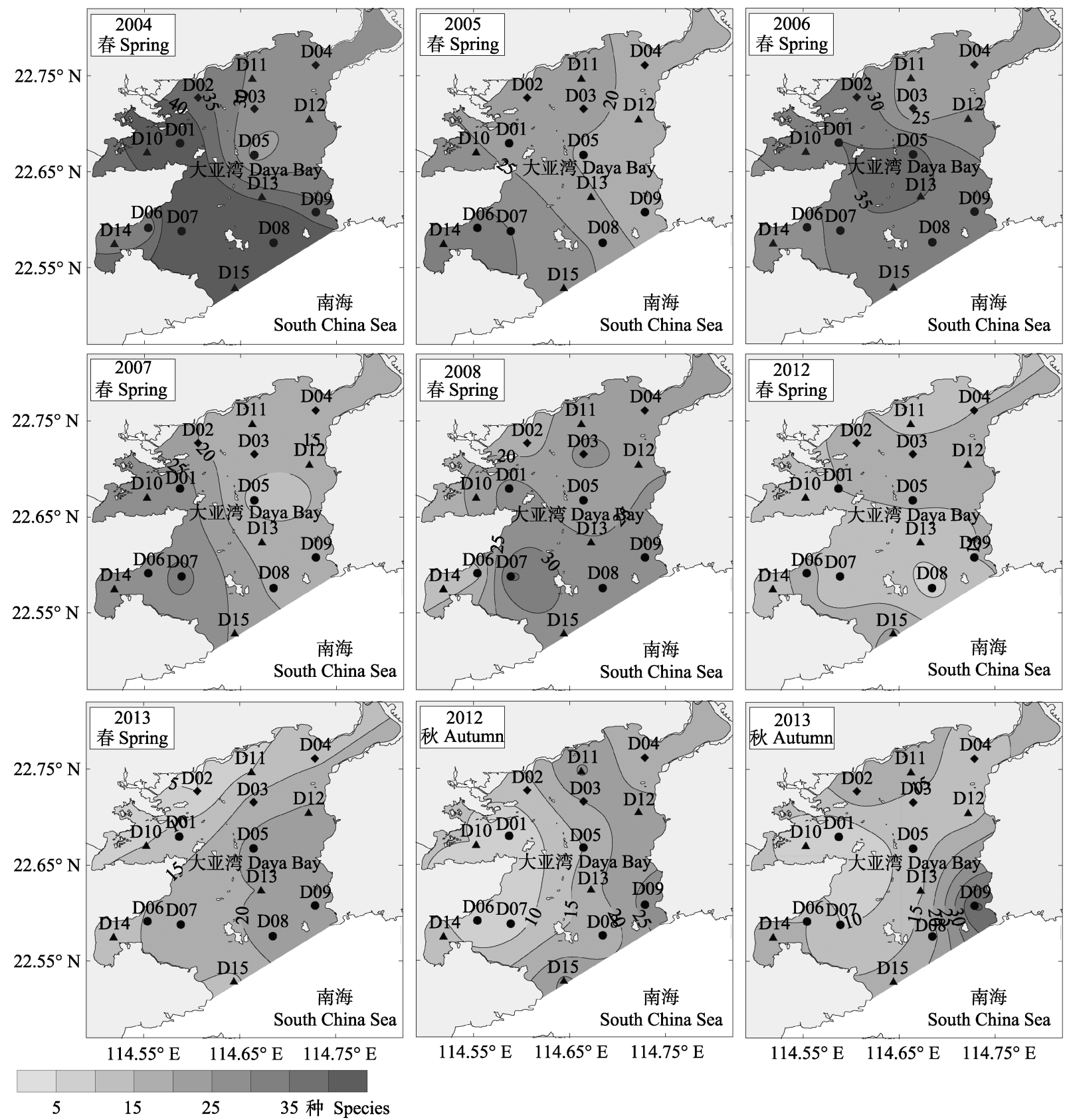

图5 2004-2008年春季和2012-2013年春、秋季大亚湾底拖网物种数量的空间变化

Fig. 5 Contour map of species number from benthic trawling in Daya Bay in spring from 2004 to 2008, spring and autumn from 2012 to 2013

虾(Metapenaeopsis barbata)、伪装仿关公蟹(Dorippoides facchino)、隆线强蟹(Eucrate crenata) 和变态 蟳(Charybdis (Charybdis) variegata)。自2004年以来, 除口虾蛄在春季和须赤虾在秋季出现较少外, 其他 优势种在不同航次的调查中基本都有出现。不同年 份甲壳动物优势种差别较大, 口虾蛄和须赤虾在 2009年前常为夏季的优势种, 伪装仿关公蟹和隆线 强蟹在2011年后常为夏、秋季优势种, 而变态蟳作
为优势种则出现在春、秋季。

(4) 软体动物腹足类的白龙骨乐飞螺 (Lophiotoma leucotropis)、棒锥螺(Turritella bacillum)、玻璃壳蛞蝓(Philine infortunata) 和假奈拟塔螺 (Turricula nelliae), 双壳类的波纹巴非蛤(Paratapes undulatus)、鳞片帝汶蛤(Timoclea imbricata)、美叶 雪蛤 (Placamen lamellatum) 和锒边鸟蛤 (Vepricardium coronatum)。春季各优势种在不同航次基本都 
表2 2004-2015年夏季大亚湾底拖网海区优势种统计

Table 2 Dominant species from benthic trawling in Daya Bay in summer from 2004 to 2015

\begin{tabular}{|c|c|c|c|c|c|c|c|c|c|c|c|c|c|}
\hline \multicolumn{2}{|c|}{ 优势种 Dominant species } & \multirow{2}{*}{$\begin{array}{l}2004 \\
++\end{array}$} & \multirow{2}{*}{$\begin{array}{l}2005 \\
-\end{array}$} & \multirow{2}{*}{$\begin{array}{l}2006 \\
-\end{array}$} & \multirow{2}{*}{$\begin{array}{l}2007 \\
-\end{array}$} & \multirow{2}{*}{$\begin{array}{l}2008 \\
++\end{array}$} & \multirow{2}{*}{$\begin{array}{l}2009 \\
+\end{array}$} & \multirow{2}{*}{$\begin{array}{l}2010 \\
-\end{array}$} & \multirow{2}{*}{$\begin{array}{l}2011 \\
+\end{array}$} & \multirow{2}{*}{$\begin{array}{l}2012 \\
+\end{array}$} & \multirow{2}{*}{$\begin{array}{l}2013 \\
-\end{array}$} & \multirow{2}{*}{$\begin{array}{l}2014 \\
-\end{array}$} & \multirow{2}{*}{$\begin{array}{l}2015 \\
+\end{array}$} \\
\hline 海地瓜 & Acaudina molpadioides & & & & & & & & & & & & \\
\hline 扁拉文海胆 & Lovenia subcarinata & ++ & + & - & - & - & + & + & + & + & - & - & - \\
\hline 光滑倍棘蛇尾 & Amphioplus laevis & + & + & + & - & + & - & - & ++ & +++ & - & + & + \\
\hline 长鯺蓝子鱼 & Siganus canaliculatus & ++ & + & + & ++ & + & +++ & + & - & + & + & +++ & + \\
\hline 四线天竺鲖 & Ostorhinchus fasciatus & ++ & + & ++ & + & + & + & + & + & + & + & + & + \\
\hline 基岛䲝 & Callionymus kaianus & ++ & + & + & ++ & + & - & + & + & + & - & + & + \\
\hline 口虾姑 & Oratosquilla oratoria & + & + & + & + & ++ & ++ & + & + & + & + & + & + \\
\hline 须赤虾 & Metapenaeopsis barbata & ++ & + & + & + & +++ & ++ & + & - & + & + & - & - \\
\hline 伪装仿关公蟹 & Dorippoides facchino & + & + & + & + & + & + & + & ++ & + & + & + & + \\
\hline 隆线强蟹 & Eucrate crenata & + & + & + & + & + & + & + & + & ++ & + & ++ & ++ \\
\hline 变态蟳 & Charybdis (Charybdis) variegata & + & + & + & + & + & + & + & + & + & + & + & + \\
\hline 玻璃壳蛞蝓 & Philine infortunata & - & - & - & - & - & - & + & + & + & + & - & + \\
\hline 白龙骨乐飞螺 & Lophiotoma leucotropis & ++ & + & ++ & ++ & ++ & + & + & + & + & + & + & + \\
\hline 假奈拟塔螺 & Turricula nelliae & ++++ & + & ++ & ++ & ++ & ++ & ++ & + & + & + & ++ & ++ \\
\hline 棒雉螺 & Turritella bacillum & +++ & + & ++++ & +++ & ++++ & ++++ & ++++ & ++++ & ++++ & ++++ & ++++ & ++++ \\
\hline 美叶雪蛤 & Placamen lamellatum & + & + & ++ & ++ & + & ++ & +++ & ++ & + & + & + & + \\
\hline 波纹巴非蛤 & Paratapes undulatus & ++ & + & ++ & ++++ & + & + & + & ++ & ++ & ++ & ++ & +++ \\
\hline 鳞片帝汶蛤 & Timoclea imbricata & + & ++++ & +++ & ++ & - & - & + & +++ & + & - & - & + \\
\hline 锒边鸟蛤 & Vepricardium coronatum & + & +++ & + & + & ++ & + & + & ++ & + & + & + & ++ \\
\hline 短吻铲荚螠 & Listriolobus brevirostris & ++ & + & - & - & + & + & + & - & + & +++ & ++ & + \\
\hline
\end{tabular}

++++ 海区第一优势种; +++ 海区第二优势种; ++ 海区优势种; + 在海区出现; - 未在海区出现。

++++ First dominant species; +++ Second dominant species; ++ Dominant species; + Present; - Not present.

表3 2004-2013年春、秋季大亚湾底拖网海区优势种统计

Table 3 Dominant species from benthic trawling in Daya Bay in spring and autumn from 2004 to 2013

\begin{tabular}{|c|c|c|c|c|c|c|c|c|c|c|c|}
\hline \multirow{2}{*}{$\begin{array}{l}\text { 优势种 } \\
\text { Dominant species }\end{array}$} & & \multicolumn{7}{|c|}{ 春季 Spring } & \multicolumn{3}{|c|}{ 秋季 Autumn } \\
\hline & & 2004 & 2005 & 2006 & 2007 & 2008 & 2012 & 2013 & 2011 & 2012 & 2013 \\
\hline 海地瓜 & Acaudina molpadioides & + & - & - & + & + & + & - & + & - & - \\
\hline 扁拉文海胆 & Lovenia subcarinata & ++ & + & + & + & + & + & - & + & - & - \\
\hline 光滑倍棘蛇尾 & Amphioplus laevis & + & - & + & + & + & + & + & ++ & + & + \\
\hline 长鯺蓝子鱼 & Siganus canaliculatus & - & - & - & + & - & + & - & - & + & + \\
\hline 四线天竺鲷 & Ostorhinchus fasciatus & + & - & + & + & - & - & - & + & + & + \\
\hline 基岛衔 & Callionymus kaianus & + & ++ & + & + & + & + & - & ++ & - & - \\
\hline 口虾姑 & Oratosquilla oratoria & + & - & + & - & + & + & - & + & + & + \\
\hline 须赤虾 & Metapenaeopsis barbata & + & + & + & - & + & + & + & + & - & - \\
\hline 伪装仿关公蟹 & Dorippoides facchino & + & - & + & + & + & + & + & ++ & ++ & + \\
\hline 隆线强蟹 & Eucrate crenata & + & + & + & + & + & + & + & ++ & + & + \\
\hline 变态蟳 & Charybdis (Charybdis) variegata & + & ++ & + & + & + & ++ & + & ++ & + & + \\
\hline 玻璃壳蛞蝓 & Philine infortunata & + & + & - & + & + & ++ & ++ & + & + & + \\
\hline 白龙骨乐飞螺 & Lophiotoma leucotropis & + & + & + & + & + & + & + & + & - & - \\
\hline 假奈拟塔螺 & Turricula nelliae & ++ & ++ & + & + & + & + & + & ++ & + & + \\
\hline 棒雉螺 & Turritella bacillum & ++ & ++ & + & +++ & +++ & +++ & +++ & ++++ & ++++ & ++ \\
\hline 美叶雪蛤 & Placamen lamellatum & ++ & ++ & + & + & + & ++ & + & +++ & + & + \\
\hline 波纹巴非蛤 & Paratapes undulatus & +++ & ++++ & + & ++ & + & ++++ & ++++ & ++ & + & + \\
\hline 鳞片帝汶蛤 & Timoclea imbricata & ++++ & +++ & ++++ & ++++ & ++++ & - & + & - & - & ++++ \\
\hline 锒边鸟蛤 & Vepricardium coronatum & + & ++ & + & + & + & + & ++ & + & +++ & +++ \\
\hline 短吻铲荚螠 & Listriolobus brevirostris & ++ & + & - & - & - & + & ++ & + & + & + \\
\hline
\end{tabular}

++++ 海区第一优势种; +++ 海区第二优势种 +++ 海区优势种 $;+$ 在海区出现; - 未在海区出现。

++++ First dominant species; +++ Second dominant species; ++ Dominant species; + Present; - Not present. 


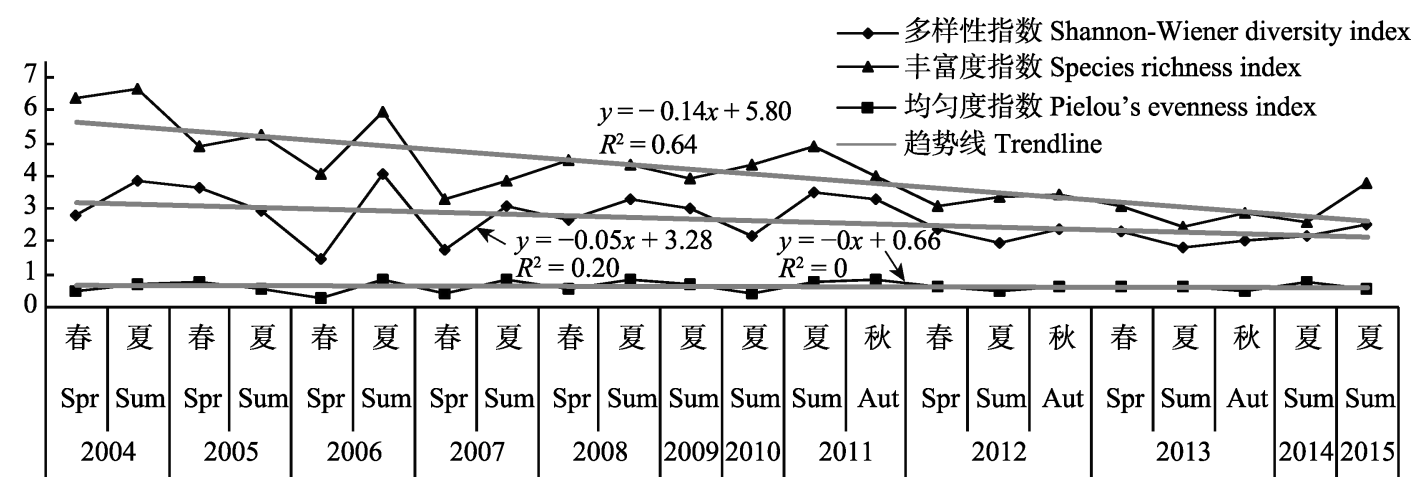

图6 2004-2015年大亚湾底拖网生物种类Shannon-Wiener指数 $\left(H^{\prime}\right)$ 、种类均匀度指数 $\left(J^{\prime}\right)$ 和种类丰富度指数 $(d)$ 的变化规律 Fig. 6 Variation of Shannon-Wiener diversity index $\left(H^{\prime}\right)$, Pielou's evenness index $\left(J^{\prime}\right)$ and Species richness index $(d)$ from benthic trawling in Daya Bay between 2004 and 2015

有出现。2008年前(除2005年)春季海区第一优势种 为鳞片帝汶蛤, 其他年份为波纹巴非蛤, 棒雉螺在 2007年后作为海区的第二优势种出现。夏季玻璃壳 蛞蝓在2009年前没有出现; 鳞片帝汶蛤在不同年份 夏季航次的出现频率变化较大, 且2008-2009年和 2013-2014年在海区没有出现; 其他优势种在夏季 调查中都有出现。2007年前夏季海区第一优势种常 发生变化, 之后棒雉螺成为海区的第一优势种, 但 第二优势种经常变化。假奈拟塔螺、波纹巴非蛤和 锒边鸟蛤常在夏季作为优势种出现。秋季除白龙骨 乐飞螺和鳞片帝汶蛤的出现频率较低外, 其他优势 种在不同航次均有出现。与夏季相同, 秋季海区的 第一优势种常为棒雉螺, 但2013年鳞片帝汶蛤为海 区的第一优势种。秋季第二优势种为美叶雪蛤或锒 边鸟蛤, 与春、夏季不同。

(5) 螠虫动物短吻铲荚螠 (Listriolobus brevirostris), 春季出现频率不高, 2006-2008年拖网调查 未采到, 但在出现的季节常为优势种。夏季该种经 常出现, 且2013年后常作为海区优势种出现。秋季 该生物也常出现，但优势度不高。

\section{4 物种多样性指数}

2004-2015年大亚湾底拖网海洋生物ShannonWiener指数 $\left(H^{\prime}\right)$ 平均值的变化范围为 $1.46-4.05$, 种 类均匀度指数 $\left(J^{\prime}\right)$ 平均值的变化范围为 $0.30-0.89$, 种类丰富度 $(d)$ 平均值的变化范围为2.49-6.69 (图 6)。不同时期相比，2012年夏季前Shannon-Wiener 指数呈波动下降趋势, 2012年后处于历史较低值, 而 2013-2015年有缓慢升高的趋势; 自2004年以来, 种类丰富度指数也呈现降低的趋势, 但不同时间段 降低的幅度有所差异，2004-2007年快速降低，
2007-2014年呈缓慢降低的趋势; 种类均匀度指数 随时间呈波动变化，2009年前基本呈现春季低于夏 季的规律，而2012年后不同季节波动规律不明显。

\section{3 讨论}

\section{1 大亚湾底拖网生物种类组成及优势种}

2004-2015年大亚湾底拖网共获得海洋动物 429种, 不同时期均以鱼类、甲壳类和软体动物为主 要生物类群。2004年春季后各航次海洋生物群落相 对2004年春季物种相似性水平变化不大, 说明大亚 湾物种资源基本稳定(图3)。在相同海域，徐恭昭 (1989) 1985年春、夏、秋、冬4个航次底拖网共获得 底栖生物 183 种 (未包含鱼类), 其中软体动物 87 种, 甲壳动物 69种，棘皮动物27种。大亚湾2004-2015 年与 1985 年调查的种类组成基本相同, 海区优势种 也有很多相同种类，但2004-2015年棘皮动物种数 显著降低。1985年在大亚湾西南海域大鹏澳和西北 部哑铃湾内大量出现的棘皮动物在2004-2015年则 较少出现，且海区第一优势种(除鳞片帝汶蛤)发生 改变。

大亚湾底拖网生物优势种存在明显的季节性 变化, 春季以鳞片帝汶蛤或波纹巴非蛤为第一优势 种; 而夏季多以棒雉螺为第一优势种，第二优势种 经常发生变化。鳞片帝汶蛤为群生性生物, 夏季拖 网调查经常采集到大量颜色鲜艳且闭合完整的鳞 片帝汶蛤，但几乎全为空壳，如未仔细检查会对调 查结果产生较大影响。2011-2013年鳞片帝汶蛤在 海区的季节变化规律发生改变, 虽然夏季该种数量 依然较低，但2012年和2013年春季却未出现; 在 2011-2012年秋季未出现, 但2013年数量却极高(表 
2-3)。鳞片帝汶蛤在海区的季节性变化规律改变可 能与人类活动干扰了其繁殖习性有关。近年大亚湾 海域的营养盐结构(王友绍等, 2004)、海岸状况(于 杰等, 2014)、鱼类物种多样性(王雪辉等, 2010)和底 栖生物群落结构(杜飞雁等, 2011)都发生过一定的 变化, 出现岸线的退化、与浮游植物生长相关的营 养盐由氮限制变为磷限制和鱼类小型化等环境问 题。鳞片帝汶蛤特别是幼体的移动基本是受底层海 流控制的, 海洋开发会导致海区水动力的改变, 影 响该生物的分布。而底栖生物数量的变化, 特别是 肉食性生物的减少, 会使该生物被捕食压力降低和 摄食压力升高。

\section{2 大亚湾物种多样性的时间变化特征}

大亚湾底拖网物种多样性的季节性变化规律 并不明显, 虽然2004-2008年种类丰富度指数和 Shannon-Wiener指数在春季经常低于相邻的夏季, 但是物种数量并不呈现此变化规律, 这与鳞片帝汶 蛤大量出现在春季导致海湾相关指数的降低有关。 2012-2013年这种相邻不同季节的变化趋势已不明 显, 此时春季鳞片帝汶蛤数量相对较低。

2004-2015年各航次大亚湾底拖网海洋生物 Shannon-Wiener指数大部分时间都在 2.0 以上, 按我 国《近岸海域环境监测规范》(HJ 442-2008)推荐的 评价标准, 海区生物多样性处于一般水平以上。 2006年和2007年春季Shannon-Wiener指数小于 2.0 , 且种类均匀度相对较低, 但种类丰富度和物种数处 于历史相对较高水平, 并不能证明海湾生物多样性 低。此时, 海湾北部和西部D01, D05, D09站以北区 域Shannon-Wiener指数在 $0.001-0.098$ 之间, 指数的 降低与鳞片帝汶蛤的大量出现有关。2010年夏季与 此现象基本相同, 与棒雉螺数量极高有关。 2007-2011年夏季 Shannon-Wiener指数相对较高, 种类均匀度也较高, 但此时种类丰富度和物种数量 (平均值)处于中等水平, 表征海区物种多样性并不 是很好。2012年秋季至2014年夏季Shannon-Wiener 指数处于历史较低水平, 同时种类丰富度或物种数 较低, 虽然种类均匀度处于较高水平, 但此时海湾 物种多样性相对较低。由此认为, 导致Shannon-Wiener指数降低的原因一般有两种: 环境的退化和与 生活习性有关的某种生物个体数量极高。如果仅使 用该指数来评判生物多样性会产生一定的偏差, 而 应与其他指标结合, 综合分析生物多样性状况。
2005 年夏季至 2007 年夏季海洋生物种类数连 续降低, 与期间大亚湾北部和东部种类数量低值区 (小于 10 种)面积不断扩大有关, 至2007年夏季整个 海湾物种数量均处于较低水平(图4)。2008年后虽然 低值区依然存在, 但范围逐步缩小; 而且种类数高 值(大于 35 种)常在海湾局部区域出现, 如 2008 年春 夏季的西南区域, 2010年D05站附近的中部区域, 至2011年夏季分布范围不断扩大(D01站、D08站和 D12站), 这期间大亚湾底拖网生物种类数不断升 高。2012年后种类低值区又开始从海湾的北部和西 北部向其他海区逐年扩大, 至2014年仅湾口个别站 种类数量较高, 此时海区物种数较低且随时间波动 频繁。大亚湾物种多样性随时间的变化与海湾生物 种类数低值区的不断变化有关。

\section{3 大亚湾物种多样性的空间分布特征}

2004年以来大亚湾物种数的空间分布出现了 较大变化。2007年前, 春季湾内东高西低, 夏季湾 口高于湾北部且向湾口西南部逐渐升高; 而2008年 后, 不同季节基本呈现湾北部向湾东南或南部升高 的趋势, 大亚湾北部物种数量显著下降, 2013年后 在大亚湾西北部的D01站附近底拖网已经很难拖到 海洋生物, 同时导致这些区域生物多样性指数显著 降低(图4, 图5)。由此推断, 大亚湾种类数量空间分 布是存在季节性差异的, 而近年由于外界的干扰, 季节性变化不再明显。2004年后大亚湾的海洋开发 活动(城市建设、港口码头建设和石化工程)主要集 中在大亚湾的中北部, 工程建设初期会对海洋环境 产生较大的干扰。大亚湾海洋开发活动依托的是优 良的自然环境和水上交通条件, 徐恭昭(1989)报道 大亚湾中北部大部分为 $5 \mathrm{~m}$ 以下的浅水区域, 而目 前海湾中北部的马鞭洲石化码头和西北部的惠州 港都具有停泊 10 万吨级以上船舶的能力, 要求航道 水深在 $10 \mathrm{~m}$ 以上。不定期的疏浚清理作业, 会对该 区域的水动力和底栖环境产生一定影响。李纯厚等 (2015)根据2007年大亚湾综合调查数据评价了其生 态系统健康水平, 认为该湾的生态系统健康水平呈 现由海湾的东部向西部降低的趋势。

\section{4 大亚湾物种多样性受人类活动的影响}

2004-2015年底拖网海洋生物种类数、种类丰 富度指数和Shannon-Wiener指数均指示大亚湾海洋 生物多样性随时间呈退化的趋势, 且近几年几乎都 处于较低的水平(图2, 图6)。大亚湾物种多样性的降 
低可能与人类活动的干扰有关。近年大亚湾北部物 种数出现显著的降低, 该区域常采到大量颜色鲜艳 的贝壳, 但是壳中却是恶臭的黑泥(附录1)。大亚湾 的港口、石化开发和围填海活动主要集中于该区域 (于杰等，2014)。2004-2007年大亚湾西北部的D01 站物种数一直处于海区较高的水平, 而之后物种数 显著降低, 特别是在2013年D01站和D10站已经采 集不到海洋生物(图4，图5)。该区域同时也是大亚湾 赤潮频发的区域(彭云辉等, 2002)。据惠州市的统计 公报报道 (http://www.hzsin.gov.cn/tjgb/index.htm), 2007年后惠州港的吞吐量出现了快速的增长, 港口 的扩建和航道维护疏浚会对周围海域环境产生影 响。如果该海域在未来十几年再进行大量的填海建 港工程, 将会导致该区域底栖生物物种多样性恢复 困难。

大亚湾东北部的D03站和D04站受惠州石化炼 油基地围填海的影响, 同时该区域也是开展水产养 殖的重要场所, 2005年后该区域生物多样性一直处 于海区中等偏下水平。D05站位于大亚湾马鞭洲岛 附近, 2007-2009年该站物种数量显著降低, 与马鞭 洲石化基地扩建和深水码头的建设时期基本同步 (黄忠平和黄瑞灵, 2012)。同时由于马鞭洲岛的空间 限制, 石化码头建设完成后已没有空间再进行拓展, 之后该区域受到的干扰活动主要是航道的通行和 维护, 其中航道的疏浚活动对底栖环境的影响最大, 而该影响是不定期存在的, 导致该区域生物物种数 量波动较大，如2010年该区域物种多样性有所恢复， 但之后又出现降低, 而2015年夏季该区域海区物种 多样性达到历史较高水平。

大亚湾东南部的D09站, 在 2008 年夏季调查中 物种数锐减, 与平海电厂码头港池和航道的施工期 基本相同, 虽然之后物种数量迅速恢复, 但波动相 对频繁, 码头建成后不定期进行的航道维护疏浚会 对底栖环境产生影响。D06站和D07站位于大亚湾 的西南部, 在 2007 年春季前物种数量的变化不大, 但之后不同航次调查结果出现明显的波动, 可能与 该区域长期受大亚湾核电站温排水的影响有关, 同 时D07站位于惠州港西侧出海航道附近, 也会受航 道维护疏浚的影响。大亚湾口的D08站位于惠州石 化码头和港口的马鞭洲航道附近, 目前该航道可单 向航行 30 万吨超级油轮, 航道通行和维护会对其产 生一定影响。
目前, 大亚湾北部的物种多样性退化严重, 几 乎已经失去了物种资源维持的功能。就整个海湾而 言, 海洋物种多样性虽然出现一定程度的下降, 但 物种资源基本稳定，只是目前由部分区域承担了历 史上全海湾物种多样性维持的功能, 生境的弹性变 小, 生态系统将变得更加脆弱。大亚湾海域底栖生 态系统受到的人为干扰活动主要是围填海、港口建 设、航道疏浚维护及海洋养殖。

\section{5 底拖网和定量采泥调查结果的比较}

底拖网与定量采泥调查的生物种类和优势种 存在明显的差异。定量调查的大亚湾生物种类组成 以环节动物多毛类、甲壳动物和软体动物为主(江锦 祥等, 1990a, b; 张敬怀等, 2007; 杜飞雁等, 2008, 2011)。而2004-2015年底拖网的主要生物类群为软 体动物、甲壳动物和鱼类, 多毛类仅获得 21 种。江 锦祥等(1990 a, b) 1987年3月和9月在大亚湾定量采 泥和底拖网获得底栖生物 473 种, 而以定量分析海 区优势种为双鳃内卷齿蚕 (Aglaophamus dibranchis)、袋稚齿虫(Prionospio ehlersi)、联珠蚶(Anadara consociata)、粗帝汶蛤(Timoclea scabra)、波纹巴非 蛤、模糊新短眼蟹(Neoxenophthalmus obscurus) 和光 滑倍棘蛇尾等。杜飞雁等(2011)利用2008年四季在 大亚湾定量采泥的调查数据分析海区优势种为粗 帝汶蛤、毛头梨体星虫 (Apionsoma (Apionsoma) trichocephalus)、脑纽虫(Cerebratulina $\mathrm{sp}$.)、独毛虫

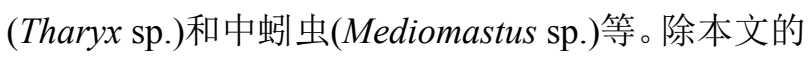
鳞片帝汶蛤可能与粗帝汶蛤同种外, 其他优势种均 未在2004-2015年底拖网中出现。

底拖网的最小网目在 $7 \mathrm{~mm}$ 左右, 是大型底栖 生物定量调查的最小网目 $(0.5 \mathrm{~mm})$ 的 12 倍, 获得的 海洋生物个体相对较大。定量调查很少采集到生活 在海洋底层具有一定运动能力的鱼类, 获得的生物 功能群营养级相对较低, 如大亚湾底拖网调查经常 获得一些高营养级海洋生物尖尾鳗(Uroconger lepturus)、马六甲虫鳗(Muraenichthys thompsoni)、尖 吻蛇鳗 (Ophichthus apicalis) 和短蛸 (Amphioctopus fangsiao) 等。底栖生物拖网和定量调查是探索海洋 底栖物种多样性的两个重要手段, 获得的结果具有 一定的互补性。由于我国大量开展海洋生物调查时, 西方发达国家已经进入了底栖生物定量调查阶段。 此时, 我国虽然在开展底栖生物调查时也进行了大 量的拖网调查, 但数据分析主要针对定量调查结果 
进行, 而对定性拖网数据的分析不够, 并未对底拖 网生物种类组成、主要生物物种和群落状况进行深 入分析，导致现在我国对近岸大型底栖生物多样性 的认识存在一定的欠缺。频繁的底拖网会对底栖生 态环境产生一定的影响, 需合理规划底拖网调查在 海洋生物多样性调查与监测中的使用, 为摸清我国 海洋生物多样性提供多元数据。

致谢: 感谢国家海洋局南海环境监测中心各位同事 对大亚湾底拖网工作的支持; 感谢中国海洋大学刘 小收博士对本文提出的修改建议; 对于编委和编辑 为本文付出的辛苦工作由衰的感谢!

\section{参考文献}

Cai LZ (2006) Progress on marine benthos ecology and biodiversity. Journal of Xiamen University (Natural Science), 45(Suppl. 2), 83-89. (in Chinese with English abstract) [蔡 立哲 (2006) 海洋底栖生物生态学和生物多样性研究进 展. 厦门大学学报, 45(Suppl. 2), 83-89.]

Dai AY, Yang SL, Song YZ, Chen GX (1986) Marine Crab of China. China Ocean Press, Beijing. (in Chinese) [戴爱云, 杨思谅, 宋玉枝, 陈国孝 (1986) 中国海洋蟹类. 海洋出 版社, 北京.]

Dong ZZ (1991) Biology of the Economic Species of Cephalopods in the World Oceans. Shandong Science and Technology Press, Ji'nan. (in Chinese) [董正之 (1991) 世界大 洋经济头足类生物学. 山东科学技术出版社, 济南.]

Du FY, Wang XH, Jia XP, Yang SY, Ma SW, Chen HG, Li CH (2011) Species composition and characteristics of macrobenthos fauna in Daya Bay, South China Sea. Journal of Fishery Sciences of China, 18, 877-892. (in Chinese with English abstract) [杜飞雁, 王雪辉, 贾晓平, 杨圣云, 马胜 伟, 陈海刚, 李纯厚 (2011) 大亚湾海域大型底栖生物种 类组成及特征种. 中国水产科学, 18, 877-892.]

Du FY, Zhang HH, Li CH, Wang XH, Jia XP (2008) Species composition and diversity of macrobenthos fauna in Daya Bay. Journal of Fishery Sciences of China, 15, 253-260. (in Chinese with English abstract) [杜飞雁, 张汉华, 李纯厚, 王雪辉, 贾晓平 (2008) 大亚湾大型底栖动物种类组成 及物种多样性. 中国水产科学, 15, 253-260.]

Huang ZG, Lin M (2012) An Illustrated Guide to Species in China's Sea, Vols. 3-8. China Ocean Press, Beijing. (in Chinese) [黄宗国, 林茂 (2012) 中国海洋生物图集, 第三 一八册. 海洋出版社, 北京.]

Huang ZP, Huang RL (2012) On Huizhou's port economy development. Journal of Huizhou University, 32(5), 21-24. (in Chinese with English abstract) [黄忠平, 黄瑞灵 (2012) 惠 州港口经济发展探析. 惠州学院学报, 32(5), 21-24.]

Institute of Zoology of Chinese Academy of Sciences, Institute of Oceanography of Chinese Academy of Sciences, Shanghai Fisheries College (1962) Fishes of South China Sea. Science Press, Beijing. (in Chinese) [中国科学院动物研究 所, 中国科学院海洋研究所, 上海水产学院 (1962) 南海 鱼类志. 科学出版社, 北京.]

Jaccard P (1908) Nouvelles recherches sur la distribution florale. Bulletin de la Société vaudoise des sciences naturelles, 44, 223-270.

Jiang JX, Cai EX, Wu QQ, Xu HZ, Li RG, Zheng FW, He MH, Lin SD, Huang XG (1990a) Species composition and quantitative distribution on benthos animals in Daya Bay. In: Collections of Papers on Marine Ecology in the Daya Bay (II) (ed. Third Institute of Oceanography, State Oceanic Administration), pp. 237-247. China Ocean Press, Beijing. (in Chinese with English abstract) [江锦祥, 蔡尔西, 吴启 泉, 徐惠州, 李荣冠, 郑凤武, 何明海, 林双淡, 黄心光 (1990a) 大亚湾底栖生物的种类组成和数量分布. 见: 大 亚湾海洋生态文集(II) (国家海洋局第三海洋研究所编), 237-247页. 海洋出版社, 北京.]

Jiang JX, Li RG, Zheng FW, Lu L, Wu QQ, Xu HZ, Huang XG (1990b) Analysis of benthos community structure in Daya Bay. In: Collections of Papers on Marine Ecology in the Daya Bay (II) (ed. Third Institute of Oceanography, State Oceanic Administration), pp. 282-289. China Ocean Press, Beijing. (in Chinese with English abstract) [江锦祥, 李荣 冠, 郑风武, 鲁琳, 吴启泉, 徐惠州, 黄心光 (1990b) 大 亚湾底栖动物群落结构分析. 见: 大亚湾海洋生态文集 (II) (国家海洋局第三海洋研究所编), 282-289页. 海洋出 版社, 北京.]

Li CH, Xu SN, Du FY, Lin L (2015) Responses of the Daya Bay ecosystem to human activities and health assessment. Chinese Fishery Quality and Standards, 5(1), 1-10. (in Chinese with English abstract) [李纯厚, 徐姗楠, 杜飞雁, 林 琳 (2015) 大亚湾生态系统对人类活动的响应及健康评 价. 中国渔业质量与标准, 5(1), 1-10.]

Li SZ, Wang HM (1995) Fauna Sinica: Ostichthyes Tleuronectiformes. Science Press, Beijing. (in Chinese) [李思忠, 王 惠民 (1995) 中国动物志 硬骨鱼纲 鲽形目. 科学出版 社, 北京.]

Liao YL (2004) Fauna Sinica: Invertebrata, Vol. 40, Echinodermata Ophiuroidea. Science Press, Beijing. (in Chinese) [廖玉麟 (2004) 中国动物志 无脊椎动物 第四十卷 棘皮 动物门 蛇尾纲. 科学出版社, 北京.]

Liao YL (1997) Fauna Sinica: Phylum Echinodermata Class Holothuroidea. Science Press, Beijing. (in Chinese) [廖玉麟 (1997) 中国动物志棘皮动物门海参纲. 科学出版社, 北京. ]

Liu RY, Zhong ZR (1986) Penaeoid Shrimps of the South China Sea. Agricultural Publishing House, Beijing. (in Chinese) [刘瑞玉, 钟振如 (1986) 南海对虾类. 农业出版社, 北京.]

Margalef R (1958) Information theory in ecology. International Journal of General Systems, 3, 36-71. 
Peng YH, Sun LH, Chen HR, Wang ZD (2002) Study on eutrophication and change of nutrients in the Daya Bay. Marine Science Bulletin, 21(3), 44-49. (in Chinese with English abstract) [彭云辉, 孙丽华, 陈浩如, 王肇鼎 (2002) 大亚湾海区营养盐的变化及富营养化研究. 海洋通报, 21(3), 44-49.]

Qi ZY (2004) Seashells of China. China Ocean Press, Beijing.

Wang XH, Du FY, Qiu YS, Li CH, Sun DR, Jia XP (2010) Variations of fish species diversity, faunal assemblage, and abundances in Daya Bay in 1980-2007. Chinese Journal of Applied Ecology, 21, 2403-2410. (in Chinese with English abstract) [王雪辉, 杜飞雁, 邱永松, 李纯厚, 孙典荣, 贾 晓平 (2010) 1980-2007年大亚湾鱼类物种多样性、区系 特征和数量变化. 应用生态学报, 21, 2403-2410.]

Wang YS, Wang ZD, Huang LM (2004) Environment changes and trends in Daya Bay in recent 20 years. Journal of Tropical Oceanography, 23(5), 85-95. (in Chinese with English abstract) [王友绍, 王肇鼎, 黄良民 (2004) 近20年来大亚 湾生态环境的变化及其发展趋势. 热带海洋学报, 23(5), 85-95.]

Wang ZD, Lian JS, Hu JX, Wei GF (2003) Characteristics of degraded ecosystem in Daya Bay, China. Ecological Science, 22, 313-320. (in Chinese with English abstract) [王肇 鼎, 练健生, 胡建兴, 韦桂峰 (2003) 大亚湾生态环境的 退化现状与特征. 生态科学, 22, 313-320.]

Wei CD, Chen YS (1991) Fauna of Zhejiang: Crustacea. Zhejiang Science and Technology Publishing House, Hangzhou. (in Chinese) [魏崇德, 陈永寿 (1991) 浙江动物志 甲壳类. 浙江科学技术出版社, 杭州.]

Xu GZ (1989) Environments and Resources of Daya Bay. Anhui Science and Technology Publishing House, Hefei. (in Chinese) [徐恭昭 (1989) 大亚湾环境与资源. 安徽科学
技术出版社，合肥.]

Xu ZL, Chen YQ (1989) Aggregated intensity of dominant species of zooplankton in autumn in the East China Sea. Chinese Journal of Ecology, 8(4), 13-15. (in Chinese with English abstract) [徐兆礼, 陈亚篗 (1989) 东黄海秋季浮 游动物优势种聚集强度与蛤鯺渔场的关系. 生态学杂志, 8(4), 13-15.]

Yu J, Chen GB, Huang ZR, Chen ZZ (2014) Changes in the coastline of three typical bays in Guangdong during recent 10 years revealed by satellite image. Transactions of Oceanology and Limnology, (3), 91-96. (in Chinese with English abstract) [于杰，陈国宝，黄梓荣，陈作志 (2014)近10年 间广东省 3 个典型海湾海岸线变迁的遥感分析. 海洋湖沼 通报, (3), 91-96.]

Zhang FY, Liao YL, Wu BL, Cheng LR (1964) Illustrations of Chinese Fauna: Echinodermata. Science Press, Beijing. (in Chinese) [张凤瀛, 廖玉麟, 吴宝铃, 程丽仁 (1964) 中国 动物图谱 棘皮动物. 科学出版社, 北京.]

Zhang JH, Xiao YZ, Wang H, Lin D, Dong YH (2007) Analysis of community structure on macrobenthos in sea area around Daya Bay Nuclear Power Station. Marine Environmental Science, 26, 561-564. (in Chinese with English abstract) [张敬怀，肖瑜璋，王华，林端，董燕红 (2007) 大 亚湾核电站邻近海域大型底栖生物群落结构分析. 海洋 环境科学, 26, 561-564.]

Zhou H, Li FL, Wang W (2007) Fauna Sinica: Invertebrata, Vol. 46, Sipuncula Echiura. Science Press, Beijing. (in Chinese) [周红, 李风鲁, 王玮 (2007) 中国动物志 无脊椎动 物 第四十六卷星虫动物门螠虫动物门. 科学出版社, 北京.]

(责任编委: 李新正 责任编辑: 问文杰)

\section{附录 Supplementary Material}

附录1 大亚湾底栖生物底拖网调查及 2013 年在大亚湾北部采到的大量锒边鸟蛤空壳图。A: 底拖网; B, C: 锒边鸟蛤及壳内 的黑泥。

Appendix 1 Benthic trawling survey and empty shell of Vepricardium coronatum from the northern Daya Bay in 2013. A, Benthic trawling; B, C, Vepricardium coronatum with black and stinking muddy.

http://www.biodiversity-science.net/fileup/PDF/2017103-1.pdf 
张敬怀, 高阳, 时小军, 吕向立. 大亚湾底拖网海洋生物种类组成及物种多样性. 生物多样性, 2017, 25 (9): 1019-1030.

http://www.biodiversity-science.net/CN/10.17520/biods.2017103
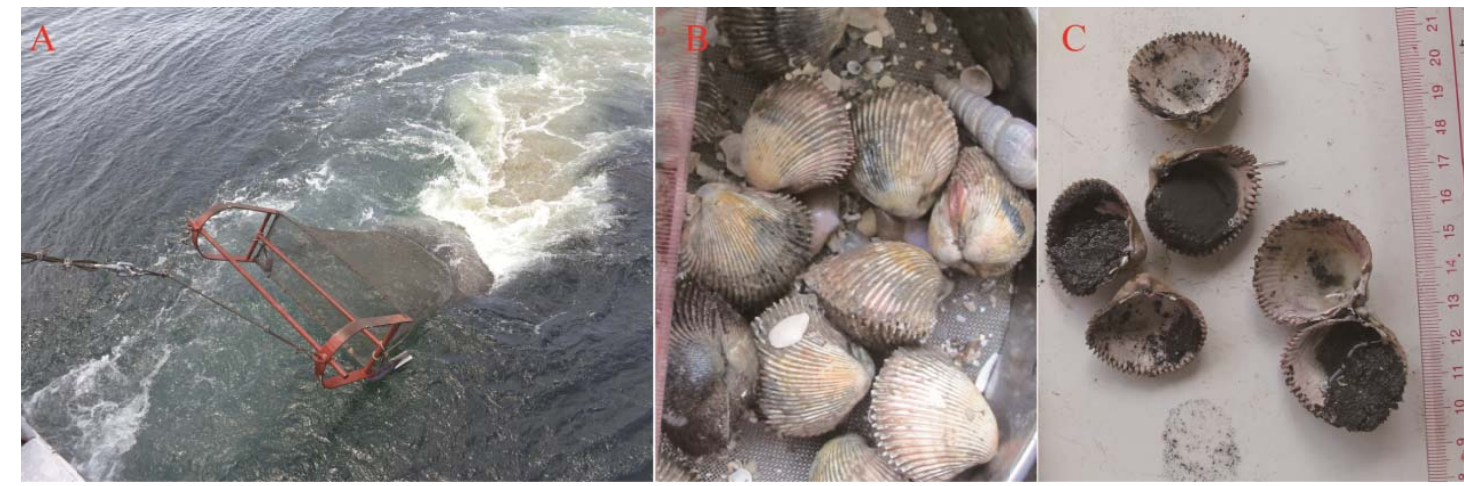

附录1 大亚湾底栖生物底拖网调查及2013年在大亚湾北部采到的大量锒边鸟蛤空壳图。A：底拖网; B, C: 锒边鸟蛤及壳 内的黑泥。

Appendix 1 Benthic trawling survey and empty shell of Vepricardium coronatum from the northern Daya Bay in 2013. A, Benthic trawling; B, C, Vepricardium coronatum with black and stinking muddy. 